\title{
Alfred de Musset, Les Caprices de Marianne
}

\section{Valentina Ponzetto}

\section{(2) OpenEdition}

\section{Journals}

\section{Édition électronique}

URL : https://journals.openedition.org/studifrancesi/3155

DOI : 10.4000/studifrancesi.3155

ISSN : 2427-5856

\section{Éditeur}

Rosenberg \& Sellier

\section{Édition imprimée}

Date de publication : 1 juillet 2013

Pagination : 474-475

ISSN : 0039-2944

\section{Référence électronique}

Valentina Ponzetto, «Alfred de Musset, Les Caprices de Marianne », Studi Francesi [En ligne], 170 (LVII I II) | 2013, mis en ligne le 30 novembre 2015, consulté le 01 février 2023. URL : http://

journals.openedition.org/studifrancesi/3155; DOI : https://doi.org/10.4000/studifrancesi.3155

\section{Ce document a été généré automatiquement le 1 février 2023}

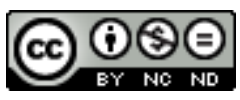

Creative Commons - Attribution - Pas d'Utilisation Commerciale - Pas de Modification 4.0 International - CC BY-NC-ND 4.0

https://creativecommons.org/licenses/by-nc-nd/4.0/ 


\title{
Alfred de Musset, Les Caprices de Marianne
}

\author{
Valentina Ponzetto
}

\section{RÉFÉRENCE}

ALFRED DE MUSSET, Les Caprices de Marianne, préface, commentaires et notes de Florence NAUGRETTE, Paris, Le Livre de Poche, 2012, pp. 188.

1 Cette édition des Caprices de Marianne est établie, comme il est désormais coutume de le faire, sur la version première et préoriginale du texte, parue dans la «Revue des deux mondes» le 15 mai 1833. Les rares variantes de l'édition originale, publiée l'année suivante dans Un Spectacle dans un fauteuil (prose) sont données en note. On n'y trouvera pas, en revanche, les variantes de l'édition traditionnellement dite «de scène», sensiblement remaniée en vue de la représentation en 1851 et publiée la même année chez Charpentier. Seul le dénouement de cette version (scènes 14-18) trouve place dans une annexe. Pour le reste, on renvoie judicieusement le lecteur intéressé à l'édition critique à paraître, procurée par Esther Pinon dans le cadre des Euvres complètes de Musset chez Champion. Florence Naugrette rappelle du reste que l'édition présentée ici est celle qu'on joue régulièrement aujourd'hui. Elle préfère donc abandonner les dénomination traditionnelles de «version de lecture» pour celle de 1833 et «version de scène» pour celle de 1851, désignant plutôt cette dernière par «version remaniée».

2 Ce choix reflète aussi une prise de position critique: Florence Naugrette est parmi les chercheurs qui militent contre la vieille idée reçue, fondée sur une interprétation trop littérale de la formule provocatrice de «spectacle dans un fauteuil», selon laquelle Musset aurait écrit ses œuvres de jeunesse, dont Les Caprices de Marianne, sans penser à la scène, pour le seule lecture donc. À cette idée elle oppose celle, radicalement différente, de «spectacle dès le fauteuil» (p. 18): reprenant une thèse déjà avancée par Loïc Chotard, elle souligne la profonde imprégnation d'actualité théâtrale de Musset, grand amoureux et fréquentateur assidu des salles de spectacle. La pièce répond donc 
«à l'appel de la scène. Non pas celle de son époque, mais celle du siècle suivant, où l'espace vide est sculpté [...] par le texte», comme le rappelle la préface, où Florence Naugrette souligne la modernité et l'efficacité de la dramaturgie mussétienne dans la gestion du temps, de l'espace et du dialogue, même (ou surtout) celui dont la facture semble la plus imagée et poétique.

3 Notre attention est attirée aussi sur le genre de la pièce, comédie inouïe, envahie par la présence de la mort, mais comédie quand même, qui fond au creuset de l'humour noir romantique des réminiscences de Shakespeare, de la commedia dell'arte italienne et de la comédie espagnole du Siglo de oro. Une fine analyse est enfin consacrée aux personnages, Octave et Cœlio, dont l'opposition et les contradictions sont mises en perspective et débarrassées de quelques idées reçues simplificatrices, et surtout Marianne. Florence Naugrette rappelle la nature fascinante et énigmatique de ce personnage, dont le comportement a suscité beaucoup d'interprétations, parfois opposées, dont elle dresse une synthèse avant de proposer la sienne: pour elle, l'héroïne est une jeune femme qui «veut juste devenir le sujet de son désir» et ses «caprices» «sont l'affirmation maladroite, chaotique et sans espoir d'une liberté féminine entravée» (p. 37).

Le volume est complété par un remarquable dossier, comprenant un riche historique de la mise en scène et un développement inédit pour une édition de poche sur la fortune cinématographique de l'œuvre, de La Règle du jeu de Renoir aux Comédies et proverbes de Rohmer. 